\title{
Service-Learning as Crucible: Reflections on Immersion, Context, Power, and Transformation*
}

\author{
Lori Pompa \\ Temple University
}

\begin{abstract}
This article explores the transformative potential of service-learning through the lens of a particular context: a course held inside a prison. This service-learning example provides an experience of total immersion. Rather than separating the service component from the course, class is held at the actual site with a group of incarcerated classmates. This kind of approach raises many questions, including how servicelearning is "done," the fragile nature of power and our approach to it, how context impacts the educational process, as well as the transformative possibilities of a "liberatory" pedagogy. Interspersed throughout the article, participants' voices illustrate the conceptual claims and reflect the collaborative nature of the venture. Though specific course elements are discussed in some detail, they are meant to suggest larger themes applicable to service-learning in general.
\end{abstract}

I didn't expect to learn so much. I didn't expect to grow and change as a result of the process. ...As I reflect on the power of this course, I am awestruck and humbled...(Catherine, Temple participant)

This student spent nearly four months in jail. Week after week she attended class with other Temple students and a group of those incarcerated at the facility. Having class inside a prison is compellingan experience that is hard to shake. And that is one reason we do it. I do not want my students to shake these encounters easily; in fact, I want the students to be shaken by them. I want them to analyze what they experience and question it all: who is locked up and why, how these decisions are made, what these institutions are all about, and what each of us can do to change the situation.

\section{Total Immersion: Learning Content through Context}

We do not learn best by memorizing facts about the subject. Because reality is communal, we learn best by interacting with it. (Palmer, 1993, p. xvii)

The gate slams shut, the key turns in the lock, and suddenly, the students and I are in a world that is no longer comfortable or predictable. This kind of learning changes lives: it disturbs where we are comfortable, challenges what we thought we knew. This is "Inside-Out," or, by its more formal title, "The Inside-Out Prison Exchange Program: Exploring Issues of Crime and Justice Behind the Walls." This is how it began.
Sometime in the mid 1990s, I took a class to meet with a group of life-sentenced men at a state prison three hours away from Temple's main campus in Philadelphia. During the facility tour, the students began discussing with the "lifers" issues of economics, politics, race and class, and-related to it all — crime and how we respond to it. One of the prisoners remarked how beneficial it would be to have an ongoing dialogue about these and other issues throughout the semester. Everyone agreed, while realizing that the distance was prohibitive. However, the seed was sown-and grew into a course that Temple has offered now for five years at two different sites: the Philadelphia Industrial Correctional Center (PICC), a county facility just 25 minutes from campus, and the State Correctional Institution at Graterford, an hour away. To date, approximately 450 students (from the "inside" and the "outside") have taken part.

Each semester, I take a group of 15-18 Temple students to one of these prisons for class. In the Fall, we meet with men in PICC; in the Spring, with women in PICC; and in the summer, with men in Graterford. We hold class once a week for 2.5 hours and address a separate topic each session, including such issues as: what prisons are really for; why people get involved in crime; the myths and realities of prison life; victims and victimization; and the distinction between punishment and rehabilitation. Except for an initial briefing and final debriefing, the entire course is conducted in prison, bringing together students and those who are incarcerated, within the setting that serves as part of the context of the learning. The students and I gain a unique window into the criminal justice system's 
vicissitudes, and the more we go in and out each week, the deeper and more complex the questions become. It leads to an exploration process: we read and observe, listen and discuss-but primarily, we experience.

I have learned so much about so many different issues, including everyday life. This class has been more than 'just a class.' It was [a] process of getting to know and understand the issues that so many [people] have to deal with every day of their lives. It was also a process of getting to know myself and realizing who and what I am. (Angela, Temple participant)

This model of service-learning affords students a total immersion that is powerful on numerous levels. They are provided direct, unadulterated exposure to the exigencies of a particular context. This immersion engenders deeper interaction and involvement, often manifesting as a statement of solidarity with those who are struggling. It is the ultimate border-crossing experience. In taking class together as equals, borders disintegrate and barriers recede. What emerges is the possibility of considering the subject matter from a new contextthat of those living within that context. The interplay of content and context provides a provocative juncture that takes the educational process to a deeper level.

\section{Walking out of that place every week was hard. It was hard because that was the moment that forced me to face the fact that not all of us were allowed to leave. ...If prison were anything other than [what] it is, it would be a lot less traumatic to walk out that door and leave someone behind it. (Elizabeth, Temple participant)}

This unique educational experience provides learning dimensions that are difficult to achieve in a traditional classroom. At its most basic level, InsideOut allows the students to take the theory they have learned and apply it in a real-world setting, while those behind the walls can place their life experiences in a larger academic framework.

"It is one thing to discuss issues of criminal justice with other prisoners, but the expansion of one's ideas, beliefs, and concepts are better challenged and stimulated by those who are outside of the process" (Tyrone, Graterford participant).

However, much more occurs in the exchangelayers of understanding that defy prediction. In our discussions, countless life lessons and realizations surface about how we as human beings operate in the world, beyond the myths and stereotypes that imprison us all.
"I just want to be human, but so much of my humanity must be buried here. ...Cell doors may not 'open up,' yet hearts have. Sometimes, that is actually a larger and more lasting accomplishment" (Tom, Graterford participant).

\section{A Fragile Calculus: \\ Power, Perception, and Patronization}

Too often community service is structured as a one-way activity in which those who have resources make decisions about the needs of those who lack resources. It is one more example of the 'haves' of our society shaping the lives of the 'have nots'.... Service ought to be a two-way relationship in which all parties give and receive.... (Rhoads, 1997, p. 127)

I must admit I have never been comfortable with the phrase "service-learning." Unless facilitated with great care and consciousness, "service" can unwittingly become an exercise in patronization. In a society replete with hierarchical structures and patriarchal philosophies, service-learning's potential danger is for it to become the very thing it seeks to eschew. And it can happen in subtle ways.

The crux of the problem revolves around power issues. If I "do for" you, "serve" you, "give to" youthat creates a connection in which I have the resources, the abilities, the power, and you are on the receiving end. It can be-while benign in intentironically disempowering to the receiver, granting further power to the giver. Without meaning to, this process replicates the "have-have not" paradigm that underlies many social problems.

One of the difficulties relates to limited or faulty perceptions of this relationship. For example, if we think in terms of assets and liabilities, it is easy to assume that many settings we utilize for servicelearning would be considered in the "liability" category. These settings are places where there are people with needs, a reality that often becomes the primary filter through which the setting or group of people is viewed. It is a question of definition, perception, judgment-not unrelated to the process of labeling. There is a difference, for example, between "a homeless man" and a man who is homeless, or between "a prisoner" and a person who is in prison. Labeling or perceiving in such a limited way skews the person's identity, resulting in a relationship with the liability, rather than with the person.

"The opening exercises allowed each person to get a glimpse into the other's humanity. Labels such as 'inmate' and 'student' fell away and were irrelevant. We were just people engaging each other on a basic human level" (Tyrone, Graterford participant). 


\section{Mutuality: Moving From "Doing For" to "Being With"}

Through the other, we come to experience the self. Mutuality is about how we both give and receive because we connect to the other through a concern, which, in the name of caring, bridges whatever differences we have. (Rhoads, 1997, p. 139)

We speak often of institutional resources of higher learning and the responsibility that we have to make those resources available to the wider community. While this notion is certainly true, it can be dangerously one-dimensional. What we may fail to see in the equation are the many ways in which the academy needs the community's assets-those tangible and intangible gifts that challenge, deepen, and enhance the higher education world. The danger is that, without mutuality, service mimics charity, and "...charity does not encourage the intimate connections and the personal relationships that result from service built on mutuality" (Rhoads, 1997, p. 128).

At its core, service-learning is about relationship"a relationship that is based on equality and collaboration.... From such a perspective, ... service is seen more as an act of working with people in need rather than working to serve them" (Rhoads, 1997, p. 8 ). The concept of relationship implies a connection, an interchange, a reciprocity between people. Everyone involved in a service-learning encountercommunity members, students, instructor-is impacted upon by the others and by the shared experience itself.

Part of service-learning's power comes from the dialogic interaction that takes place between and among those involved. This dialogue occurs on many levels and is multi-dimensional in character. It certainly includes the spoken word, through which participants share ideas, stories, perceptions, opinions-verbalizing realities with and for one another. More fundamentally, though, it is an experience through which people speak their lives, by the simple yet profound act of being together.

The approach to service-learning used in InsideOut provides a reciprocal arrangement-everyone serves, everyone is served. One group is not "teaching" the other; rather, we are all learning together. In fact, the two groups quickly become one, through a series of community-building exercises. The "service," therefore, is less about "doing for" than "being with," in a mutual exchange. In this way, if anything is "done for" those on the inside, it is being afforded value as human beings with ideas and experiences to contribute, an opportunity that is extremely rare behind bars.

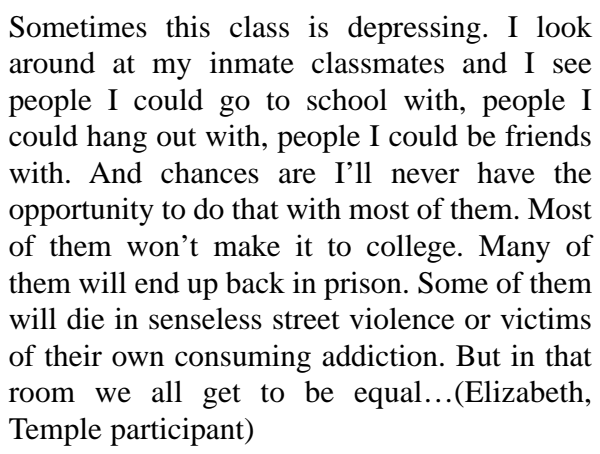

A growing number of the incarcerated men and women who have been involved have become interested in returning to school, an idea often abandoned many years before. For individuals who have been seen - and sometimes see themselves - as nothing more than a liability in life, the class offers an experience to be considered an asset, often making a significant difference in how they then envision themselves.

"Through the...women [in prison], I also learned things about life, not just about prison. Seeing the strength of these women who are living a nightmare made me stronger. I found role models in a very unlikely place" (Kim, Temple participant).

\section{Demythologization: Defying Initial Assumptions}

\begin{abstract}
That was my initial feeling of the [incarcerated] students, that they were criminals. Now that I have had this opportunity, I am much more open-minded to people. I am also not as judgmental of people as I used to be. I have learned to get to know people first, before making rash judgments about them. (Jennifer, Temple participant)
\end{abstract}

At the beginning of any college course, everyone involved-whether consciously or not-carries assumptions about those with whom they will be sharing the semester. These judgments can be based on many factors: age, skin color, accent, dress, where one sits, how one acts-whatever is picked up through visual cues. In the Inside-Out class, the usual assumptions are expanded to include perceptions of such things as intelligence, dangerousness, and trustworthiness. This results from two seemingly disparate groups coming together in one space, with the underlying presumption that their respective worlds and sets of experiences are radically different. It takes only a short time for this premise to be dispelled. We are left with one group, whose common elements emerge more prominently than their differences. 
All I could see when I sat in class was their 'blues' and I think that caused me to subconsciously form false perceptions. However, this all began to change for me when I...began to look at the [incarcerated] students as individuals, not just as blue uniforms. ...This was a very different perception from my first and was an enlightenment for me as an individual. I don't think I have ever felt such a strong change occur inside of me and it will be something that I hold inside for the rest of my life. (Gina, Temple participant)

As Robert Rhoads describes in Community Service and Higher Learning: Explorations of the Caring Self (1997),

\begin{abstract}
...overcoming our sense of alienation involves recognizing real differences, and, at the same time, understanding that we can build some common connections - that the stranger is not so different from myself and that we can engage one another in a common struggle or cause. (p. 119)
\end{abstract}

In the prison context, through direct interaction with men and women who are usually marginalized and mythologized, the myths are debunked, and the true complexity of the social justice/criminal justice nexus can be uncovered.

It is sad to see the semester come to an end. I wonder if we will see each other again and what will become of our lives. Prison rules try to keep our encounters as passive as possible, but a bond was formed that no prison rule could prevent. As hard as it was for me to break down my barriers, each of the women penetrated me with inspiration and knowledge and for that I will be forever grateful. Before I started this journey to see beyond our similar colors - their blue prison clothes and my blue uniform - they were women with no names or faces, because all I'd see was the crime not the person. Having been given the opportunity to release my feelings of opposition, through our collective efforts and intellectual exchanges, I can honestly say I'm beginning to shed the 'cop' in me. (Gladys, Temple participant)

\section{Drawing Forth: Reconstituting the Role of Teacher}

I must take responsibility for my mediator role, for the way my mode of teaching exerts a slow but steady formulative pressure on my students' sense of self and world. I teach more than a body of knowledge or a set of skills. I teach a mode of relationship between the knower and the known, a way of being in the world. That way...will remain with my students long after the facts have faded from their minds. (Palmer, 1993, p. 30)

I see my role as facilitating a learning process, by creating an atmosphere in which those involved can experience, examine, and explore. "A primary responsibility of educators is that they... recognize in the concrete what surroundings are conducive to having experiences that lead to growth" (Dewey, 1997 , p. 40). The key is to provide compelling situations, because they do just that-compel us to go further, deeper, in an attempt to understand more fully. This perspective takes the focus off the instructor as the reservoir and dispenser of knowledge, challenging learners to take increasing responsibility for their own education.

\section{My brain never stopped processing information as each student was able to add a piece to the steadily growing mosaic. For me, this is what a college class is all about. I left class with my mind racing to place all of the pieces discussed into their proper places. (Stan, Graterford participant)}

Through a participatory methodology, theoretical knowledge is enhanced and deepened in ways that are difficult to replicate within the context of a solely didactic pedagogy. If we conceive of the education process as a "drawing forth," as its etymology suggests, we can then understand these contextualized experiences as conduits through which newly integrated realizations can emerge.

In A Pedagogy for Liberation (1987), co-authored by Ira Shor and Paulo Freire, Shor mentions an example in which,

...the professor learn[s] along with the students, not knowing in advance what would result, but inventing knowledge during the class, with the students. This is a complex moment of study. ...The material of study is transformed. The relationship between the professor and the students is re-created. (p. 86)

There are many challenges in this approach, not the least of which relates to power and control. This pedagogy calls for creating an atmosphere in which there is room for the unexpected to emerge, as well as space for power to be shared among all participants.

At the inception of the Inside-Out Program five years ago, my primary focus was on the Temple students and what they would learn through this ongoing encounter. Initially, the syllabus called for the students to go to the prison every other week, and meet on campus during the alternate weeks. My assumption was that we would need to debrief each session as we went along. After the first week in the prison, however, the students strongly recommended 
that we go to the prison every week. They were concerned that, in processing separately from the rest of the group, the class would remain divided, compromising the integrity and mutuality of the exchange. Their intuition was exactly on target, and gradually led me to more deeply understand the contours of this exchange.

What a motley crew we made in that little program room at [the prison]. I often think about the incredible dynamic of our group and wonder what we must look like to the people outside that room. People of different colors, sexes, ages, education levels, social classes and opinions in a circle, laughing, talking, arguing and respecting each other for hours at a time. It has to make it difficult for anyone who watches to hold on to the status quo. The status quo says that doesn't happen. It says that people are different and that some things are never going to change. For two and a half hours every Thursday this semester, we proved that untrue. (Elizabeth, Temple participant)

In A Pedogogy for Liberation, Freire (1987) discusses the "directive" role of the teacher in this way: that the teacher is "...not directive of the students, but directive of the process. ...As director of the process, the liberating teacher is not doing something to the students but with the students [italics added]" (p. 46). This description is reminiscent of the power that Parker Palmer (1993) calls a "learning space." He suggests that this "space" emerges with a teacher,

...who not only speaks but listens, who not only gives answers but asks questions and welcomes our insights, who provides information and theories that do not close doors but open new ones, who encourages students to help each other learn. (p. 70)

I look forward to this class. I find it inspiring. There have been points, deep in our discussions, that I've found myself feeling at home. I know that sounds odd, but it's quite true. It must be from a combination of things. I think we all feel generally respected, affirmed, and supported in our opinions and world views. And I feel in this dialogue of Temple students and men on the inside an extremely critical engagement with issues of suffering and our society's accountability to the widespread phenomenon of suffering. I've been in many settings where I feel poverty, class oppression, racism were all talked about. But somehow it still just felt like words. What is spoken in the Graterford class strikes me on a much deeper level. (Anisa, Temple participant)

In facilitating the Inside-Out experience, my focus is on providing a framework within which the issues studied can be examined in depth. This exploration is mediated through an ongoing group process, in which everyone involved is afforded the space to raise questions, challenge one another, offer diverse perspectives, and wrestle with the idiosyncratic nature of our system of crime and justice. My hope is that, by the end of the semester, everyone involved has developed more than merely the ability to take in information, but the capacity to inquire, analyze, critique, challenge-or be challenged by-the information acquired.

\begin{abstract}
As much as we say we are open minded, it is not until we are forced to listen to the opinions of others that we really can appreciate the perspective that each of us brings to a subject. This was clearly instructive for me personally. (Tyrone, Graterford participant)
\end{abstract}

\section{Context: Knowing Mine, Respecting Yours, Creating Ours}

...We cannot learn deeply and well until a community of learning is created in the classroom. (Palmer, 1993, p. xvi)

In shifting the focus from passively acquiring knowledge to a fully integrated, dynamic discovery process, an essential ingredient is participatory dialogue. As its name suggests, The Inside-Out Prison Exchange Program is a course of study through which an exchange takes place involving both "inside" and "outside" students. The group generally numbers between 35 and 40, evenly divided between Temple students and men or women in the prison. This exchange offers an opportunity to delve into topics of concern in the criminal justice arena in great depth. Through both small group interaction and large group discussion, issues are grappled with in a constructive, dialogic fashion.

"Conversing with a group of individuals who have not become intellectually paralyzed by myopic points of view when discussing criminal justice issues [is] an exhilarating experience" (Paul, Graterford participant).

At the beginning of the semester, the class members develop their own guidelines for dialogue, agreed to by everyone and adhered to throughout the semester. Defining and refining these guidelines is a fascinating process, calling for a relatively large group to come to consensus on rules that will govern the group. In the process of developing these guidelines, we often model the very thing we are constructing, sometimes without even realizing it. This exercise-and how it is experienced-helps set the tone for the rest of the semester. 
[One] thing that stood out for me is how tolerant, respectful, and understanding people can be of other opinions if the parameters are established before they interact. It made me wonder why it is so easy to accomplish in the classroom and not in society. (Trevor, Graterford participant)

We do not develop these guidelines, as Freire (1987) puts it, as "... a mere technique, which we can use to help us get results" (p. 98). Though these guidelines do, in fact, keep the conversation constructive and focused, the dialogic nature of the interaction has more to do with a deep exchange, “.... moment where humans meet to reflect on their reality as they make and remake it" (p. 98). The dialogue is more a lived reality than merely a spoken one.

An issue that we explore during this guideline process is the idea of context-understanding that we each have one-and that our unique context, and all that has helped to form it, impacts how we hear, speak, and take in our surroundings. Wrestling with complex issues in which varying perspectives emerge calls for all participants to extend themselves and suspend their judgments to maximize the learning for the group as a whole.

\begin{abstract}
Even when opinions differed, it was striking to note that sometimes I thought both were right or equally reasonable. I had to redefine my concept of conflict and differences of opinion. There can be circumstances when differing opinions are equally correct, though they be mutually opposed to each other. It's not always necessary for one to be right and the other wrong. (Trevor, Graterford participant)
\end{abstract}

As Palmer (1993) puts it: “...tolerance of ambiguity can be taught as a way of listening to others without losing one's voice" (p. xviii). Additionally, understanding the relevance of context is instructive for students in a service-learning setting because it “...help(s) them understand that as human beings we do have many things in common, yet as a result of how race and class have situated us within our society, we cannot ignore important identity differences... (Rhoads, 1997, p. 123). This reality is profoundly evident in prison.

A further dimension of context refers to the setting in which the service-learning experience takes place, and its effect on everyone involved. In the prison setting, for instance, the environment has a tremendous impact on the individuals in the class, the group as a whole, as well as what is transpiring in the class. For example, simply getting into prison each week for class can become inordinately complex and frustrating. What the students glean from these experiences, however irksome, puts them in touch with the context - and inherent frustrations - of the setting in which their incarcerated classmates reside. It becomes evident that "...the self is inescapably tied to the other. And, perhaps just as important, the social context is the stage upon which the self and the other are framed" (Rhoads, 1997, p. 4).

For those imprisoned in the facility, the setting from whence they come and to which they return each class day is authoritarian and oppressive. It is an environment that is antithetical to what is necessary for a productive, creative educational process.

"During our meeting, we're no longer in the jail, we're students of Temple, and no longer...are subjected to distractions and restrictions" (Lee, Graterford participant).

Developing this sort of "liberatory" (Shor \& Freire, 1987, p. 19) environment within the prison confines can be viewed as a political act. Further, creating a space in which those incarcerated can freely explore issues that directly affect their lives holds the promise of a transformation with farreaching possibilities. Besides potentially impacting the lives and futures of those who are incarcerated, what the students are able to learn through this exchange is unparalleled. As Shor points out, "learning from reality is important, but more than just 'going to reality,' you accepted worker-students [in this case, those imprisoned] as your teachers. That adds a political depth to 'experiential' learning..." (p. 30).
It...dawned on me that having a class in a maximum security prison is...an act of resistance. By having this class, we are...questioning normative assumptions of 'criminals' and 'criminality' and normative reactions to those who have violated the law. Since society views offenders as immoral individuals who are not entitled to compassion or [to] have normal human relations, this class challenges those popular understandings. Every time we to go to Graterford and have class or even have 'normal' interactions with the guys there, we are in fact engaged in an act of resistance. It is a space that humanizes the inmates and forces all of us to deeply question the utility of the existing system of punishment. (Diditi, Temple participant)

One feature of creating a space for individuals to feel free to become engaged involves how chairs are arranged in the room. This, too, is a political statement in that it reflects how power operates in a group. In a conventional seating structure, power rests in the front of the room with the teacher. In contrast, power is shared when the seats are arranged in a circle. Palmer (1993) describes it this way:

...[W] hen the chairs are placed in a circle, creating an open space between us, within 
which we can connect,...we are all being invited to create a community of learning by engaging the ideas and one another in the open space between. (p. 75)

Class sessions were not 'classes' by the usual standard. They were safety nets, zones by which we could come together and discuss issues commonly significant to all of us, problems and solutions that we felt were important to consider and resolve. (Candy, Temple participant)

Attention and care are vital in fashioning a positive learning environment in which people feel safe. In prison, where a sense of trust is elusive, creating this setting is a challenge. Additionally, as some issues can be difficult and sensitive, the group needs to feel that the experience is contained, on the one hand, and unrestricted, on the other. Again, Palmer (1993) sheds light on both of these issues: "...[T] he openness of a space is created by the firmness of its boundaries" (p. 72); and, “...precisely because a learning space can be a painful place, it must have one other characteristichospitality. Hospitality means receiving each other, our struggles, our newborn ideas with openness and care" (p. 73).

\section{Finding Voice: Challenging the Forces that Imprison}

\begin{abstract}
My experience this semester...has not only helped me to shed some light on my own prejudices and misconceptions, but it has also strengthened and reinforced my desire to facilitate the process of growing, changing, and realizing the strength and power that is contained in a voice. (Keisha, Temple participant)
\end{abstract}

When we hold the Inside-Out class with the women in PICC, it is usually conducted in a large gymnasium, which requires our using a microphone to be heard. In one semester, what occurred as a result became the working metaphor for the class. As participants (both "inside" and "outside" students) took the microphone to speak, they backed away from it, uncomfortable with the sound of their voices echoing through the room. We began to explore this phenomenon, and discussed the difficulty, but significance, of finding one's own voice.

In our second class session, ...we talked about 'voice.' Our professor, seeing a 'teachable moment' in our resistance to the microphone, challenged us to really listen to our voices. She told us that we each have a unique 'take' on the world, and said, 'No one else has your voice.' I think that, as a group, we internalized this message. We listened to ourselves and began to call out each other's voices. (Catherine,
Temple participant)

Gradually over the succeeding weeks, individuals became more and more comfortable with the sound of their voice, confident that what they had to offer was worth the amplification that the microphone afforded.

This democracy of expression established a mutual atmosphere which encouraged the students to talk openly, not fearing ridicule or punishment for being 'stupid'... Very rarely had a professor taken them so seriously, but the truth is that they had never taken themselves so seriously either. (Shor \& Freire, 1987, p. 23)

For the...prisoners, this was probably one of the only opportunities they would have to be respected and taken seriously.... and they took advantage of it. (Elizabeth, Temple participant)

At the end of the semester, all participants used their voices with great pride to tell those gathered at the closing ceremony what the semester-long experience had meant to them. This moment was powerful for many who spoke that day, heralding an interior shift challenging those forces that once had served to imprison and render them voiceless.

\section{Prison Ironies: "Correcting" a Correctional Facility}

\begin{abstract}
That the conditions found in present experience should be used as sources of problems is a characteristic which differentiates education based upon experience from traditional education... Once more, it is part of the educator's responsibility to see equally to two things: first, that the problem grows out of the conditions of the experience being had in the present, and that it is within the range of the capacity of students; and, secondly, that it is such that it arouses in the learner an active quest for information and for production of new ideas. (Dewey, 1997, p. 79)
\end{abstract}

During the final four weeks of the semester, we work on a large project together, from which we produce a report that is submitted to the prison administration, with the hope that some of the ideas will be considered. In working through this developmental process, we deal with numerous topics, issues, and dilemmas - all grappled with in the context of working on something that has real-world applicability.

When we have class with the women, the group designs an ideal correctional facility for women, an idea inspired by plans in progress to build a new institution for women in Philadelphia. Though I am philosophically opposed to further prison construction, it nevertheless serves as yet another "teachable moment"-a project through which we examine various issues concerning incarcerated 
women within the framework of a real-world example. This exercise provides a challenge to the class to deconstruct the existing model, re-think the philosophical underpinnings of its various dimensions, and reconstruct something totally new and visionary.

During one semester, we realized in our final week that we had developed all the facility aspects except the architectural structure. I asked if anyone had an idea about where we could start and immediately one of the PICC students raised her hand and said she had a design. As I handed over the marker and sat down, she proceeded to sketch a model for the class that, with few changes, became the design adopted by the group. I remember clearly the power of that moment-for everyone involved, certainly myself included. Here was a woman who, after years of incarceration in numerous institutions, extracted from and expanded on her background to lead us where we needed to go. It was a wonderful illustration of the power that can emanate from the crucible of experience.

\section{Taking it Further: Addressing Issues of Transition}

\begin{abstract}
We have been fortunate. We have made the individual connections and are now faced with the challenge of what to do with our changed views. I don't begin to have the answers. But I have a great deal of hope.... I don't know 'how'...but I'm beginning to realize that we must also ask 'who' - and I think that together, we have found some of the courage it will take to ask and answer that question. (Catherine, Temple participant)
\end{abstract}

Last year, nearly two-thirds of the way through the semester, one woman in the class finished her jail sentence and was released. Unable to complete the Inside-Out course, Terrie called me two days after she got home to tell me that she had written another paper, and that she wanted to get together to talk about pursuing further education. We met for lunch the following day to make arrangements for her to complete the course assignments. Additionally, I connected her with a colleague who walked her through the process to begin taking classes during the summer.

Terrie was also permitted to come back into the facility for the Inside-Out Closing Ceremony, at which she spoke about her transition back home, with a special focus on making arrangements to begin her college career. This was an unprecedented event-it is a rare occurrence for a correctional facility to allow someone so recently incarcerated to return in this capacity. The moment provided a powerful inspiration to everyone in attendance.

Aware of Terrie's transition and registration process, the students from that class immediately asked about accompanying other women in their transition. The student who expressed this desire most emphatically was a former police officer (quoted earlier in this article), who had experienced a fundamental shift in perspective over the course of the semester. Various students, staff, and faculty from Temple, and others who heard about the effort, began considering the possibility of supporting more women through their transition and, where appropriate, connecting them with the resources to pursue further education. Those discussions turned into weekly meetings and became the "Transition Team," which now offers programs in a women's facility near Temple's main campus, as well as a support group for women upon their release.

This story is emblematic of what can happen when students experience the inspiration that occurs through a service-learning encounter. Intellectual understanding and analysis of issues combine with concern about and passion for those issues, propelling students to recognize their potential as change agents, ready to take the next step in addressing a particular dilemma. Different from the idea of service-learning as a "feel-good" experience, which can be transient and ephemeral, what we are talking about here involves depth, direction, hard work, and a commitment to make change in the world.

[This class] has acted as the catalyst in my passion for life and human rights, and was the pivotal point where I realigned my own path. ...[T]his program has brought me to a new understanding of life, not just in prison, but in my own life. I have acquired the concrete knowledge of the true interworkings of the system, and at the same time come to realize my own captors in life. I have heard the stories, felt the smiles, and seen the tears of women who have been to hell and back and with them I have found a voice. (Sarah, Temple participant)

\section{Change Agency: Transformative Education Realized}

I will hold its ideals and values for the rest of my life - but not only to keep them with me but to act consciously with them. (Candy, Temple participant)

According to Palmer (1993), “...the central question is whether we are educating students in ways that make them responsive to the claims of community upon their lives" (p. xvii). In providing students the opportunity to interact with the world through guided hands-on experience, and then reflect upon it, we are 
encouraging them to become agents of change, ready to meet the challenges of an increasingly complex world. In this approach, participants are engaged on many levels, increasing the likelihood of deep, lasting learning - through a blend of theory and practice in a real-world setting - that can have farreaching implications.

...[W]ith enlightenment comes responsibility. We are all responsible. What is the next step after all this dialogue is done? (Fateen, Graterford participant)

In our first class at Graterford Prison this past summer, the group's connection was so strong that the bond created in the class has continued beyond the course completion. The students and the men, many of whom are serving life sentences without parole, initiated an extension program to address the need for public education about criminal justice issues through a series of creative, literary, and media projects. Hence, theory moved seamlessly into action.

Service-learning-different from charityinvolves becoming conscientious of and able to critique social systems, motivating participants to analyze what they experience, while inspiring them to take action and make change.

Our institutions of higher learning might certainly take heed, not only by encouraging students to do such service, but by helping them to stop and mull over, through books and discussions, what they have heard and seen. This is the purpose, after all, of colleges and universities - to help one generation after another to grow intellectually and morally through study and the self-scrutiny such study can sometimes prompt. (Coles, 1993, p. 148)

After this course, I realize fully that my theoretical knowledge is only as good as what I do with it. The struggle for me is often frustrating - seeing injustice, trying to change things, sometimes failing and wondering whether anything I can do will make a real difference in people's lives. This course did not eliminate my frustrations. It intensified them. It forced me to look closely at things I may never be able to change. But in facing that, I was able to move past my frustration, to clarify my interests and abilities, and to imagine different ways of being and moving and speaking in this world. (Catherine, Temple participant)

Service-learning pedagogy has the power to turn things inside-out and upside-down for those engaged in it. It provokes one to think differently about the world, and to consider one's relationship to the world in a new way. This approach to learning captures and communicates a dynamism that inspires everyone involved to explore, inquire, and analyze. For students, spending time and sharing a space with people struggling with issues of injustice can cultivate a passion for social justice concerns. Thus, service-learning provides both an incubator for and impetus toward social change. It is transformative education at its best.

\section{Notes}

Deep gratitude is extended to Michael Szekely, research associate with the Office of Experiential Learning in the College of Liberal Arts at Temple, for his assistance and persistence in the development of this article. Additional appreciation is offered to family, friends and colleagues who provided editorial recommendations, particularly Jayne Drake, Mary Hanssens, Emily Miller and, most especially, Jill Wolfe, for her expertise and creativity.

I would like to thank the Philadelphia Prison System and the State Correctional Institution at Graterford for welcoming and supporting this program, as well as the Department of Criminal Justice and the College of Liberal Arts Dean's Office at Temple for giving me the space and encouragement to venture into some new, provocative pedagogical territory.

It is of note that Paul, the "lifer" whose idea supplied the original impetus for the Inside-Out Program, was transferred at some point after that initial discussion from the State Correctional Institution at Dallas, Pennsylvania, to Graterford. Early in 2002, when I approached Graterford about the possibility of conducting the course there, he and other lifers were instrumental in making it happen.

Finally, this article could not have been written without the input of the more than 450 "inside" and "outside" students who have taken part in eleven semesters of The Inside-Out Prison Exchange Program. I have attempted to capture the essence of this experience, and offer this paper as a tribute to the courage it has taken for them to share their lives with one another and with me. It has been a service to me as a teacher-and a humbling, liberating adventure for me as a person.

\section{References}

Coles, R. (1993). The call of service. Boston and New York: Houghton Mifflin.

Dewey, J. (1997). Experience and education. New York: Touchstone. (Original work published in 1938)

Palmer, P. J. (1993). To know as we are known: Education as a spiritual journey. New York: HarperCollins.

Rhoads, R. A. (1997). Community service and higher learning: Explorations of the caring self. New York: SUNY Press.

Shor, I., \& Freire, P. (1987). A pedagogy for liberation: Dialogues on transforming education. Connecticut and London: Bergin and Garvey. 


\section{Author}

LORI POMPA is director of Experiential Learning for the College of Liberal Arts at Temple University. Employing experiential and service-learning pedagogies in her criminal justice classes, she has taken more than 5,000 students to area correctional facilities in the past nine years, and has worked with offenders since 1985. 